\title{
Risikojustering ved måling av predikert dødelighet etter hjerteinfarkt
}

\begin{abstract}
BAKGRUNN Regjeringen innførte fra 2014 elementer av kvalitetsbasert finansiering av sykehussektoren. Overlevelse inngår som ett kvalitetsmål. Skal man benytte kvalitetsmål i finansieringen, må man være sikker på at de observerte variasjonene skyldes forhold som helseforetakene kan påvirke - ikke bakenforliggende variabler. Målet med denne studien var å undersøke hvordan predikert dødelighet etter hjerteinfarkt ble påvirket av ulike former for risikojustering.
\end{abstract}

MATERIALE OG METODE Data fra Norsk pasientregister om 10717 pasienter utskrevet med diagnosen hjerteinfarkt i 2009 ble koblet med data om sosioøkonomisk status, komorbiditet, reiseavstander og dødelighet. Predikert 30-dagersdødelighet etter hjerteinfarkt ble analysert på helseforetaksnivå med tre ulike modeller for risikojustering.

RESULTATER Den ujusterte 30-dagersdødeligheten var høyest i opptaksområdet til Helse Førde (12,5\%) og lavest i Asker og Bærum (5,2\%). Risikojustering endret estimatene for dødelighet for flere av helseforetakene. I modellen med den mest omfattende risikojusteringen var dødeligheten høyest i opptaksområdet til Akershus universitetssykehus $(10,9 \%)$ og lavest i opptaksområdet til Helse Sunnmøre (5,2\%) og Helse Nordmøre og Romsdal (5,2\%).

FORTOLKNING Variasjonen i behandlingskvalitet mellom helseforetakene målt ved predikert dødelighet etter hjerteinfarkt påvirkes av metodene som brukes for risikojustering. Hvis ordningen med kvalitetsbasert finansiering skal videreføres, bør det etableres godt dokumenterte modeller for risikojustering av kvalitetsmålene.

Kvalitetsbasert finansiering i sykehussektoren i Norge ble iverksatt fra 1 . januar $2014 \mathrm{og}$ innebærer at en andel av de regionale helseforetakenes budsjetter gjøres avhengig av kvaliteten på pasientbehandlingen slik den måles ved utvalgte kvalitetsindikatorer. I 2014 ble 497 millioner kroner avsatt til slik finansiering. Målet med ordningen er å sikre god kvalitet og pasientsikkerhet $(1,2)$.

Indikatorsettet i kvalitetsbasert finansiering i Norge er basert på både struktur-, prosess- og resultatindikatorer, til sammen 29 ulike mål (3). I utgangspunktet gir dette en bred beskrivelse av sykehusenes kvalitet, og mangfoldet i kvalitetsindikatorer kan i seg selv hindre tilfeldige utslag i budsjettildelingen. Av resultatindikatorene er det flere mål på overlevelse, blant annet 30-dagersoverlevelse etter hjerteinfarkt. Overlevelse og dødelighet er hyppig brukte kvalitetsindikatorer internasjonalt $(4,5)$. I det norske datagrunnlaget er det imidlertid ikke gjort rede for hvordan overlevelsestallene er risikojustert.

Dersom informasjon om kvalitetsvariasjoner skal benyttes som kriterium i et finansieringssystem, bør den ulikhet i kvalitet som kan observeres mellom sykehus skyldes forhold som de kan påvirke - ikke bakenforliggende variabler. Målet med denne studien var å undersøke hvordan ulike former for risikojustering påvirket predikert dødelighet etter hjerteinfarkt $\mathrm{i}$ de forskjellige helseforetakene.

\section{Materiale og metode}

Utvalg, definisjoner og data

Datasettet omfattet pasienter $\geq 18$ år utskrevet fra norske sykehus i 2009 med hoveddiagnosen hjerteinfarkt (ICD-10-kode I21 og I22). Vi benyttet 30-dagersdødelighet som kvalitetsindikator og inkluderte alle dødsårsaker.

Den metodiske tilnærmingen ble utviklet innenfor det finske PERFECT-prosjektet (6, 7) og videreutviklet innenfor EuroHOPE (8-10), et komparativt prosjekt finansiert av EUs 7. rammeprogram. Enhetene i analysen var sykehusepisoder, som startet med innleggelsen og ble avsluttet 30 dager etter den eller ved at pasienten døde (11).

Én sykehusepisode omfattet flere sykehusopphold dersom oppholdene fulgte på hverandre og tiden mellom dem var kortere enn eller lik én dag. To eller flere opphold som følge av overflytting mellom sykehus, for eksempel som følge av perkutan koronar intervensjon (PCI), ble da regnet som én sykehusepisode. Kun den første sykehusepisoden i ett år ble omfattet av analysen, det vil si at reinnleggelser ikke genererte en ny episode. Dersom sykehusene brukte forskjellige diagnoser i én episode, ble diagnosekodene fra det sykehuset som er høyest $\mathrm{i}$ hierarkiet valgt. Dersom sykehusepisoden omfattet to eller flere sykehus på samme nivå i hierarkiet, ble diagnosekodingen fra det første sykehuset i episoden benyttet.

For å bedre sammenliknbarheten i pasient-

\author{
Terje P. Hagen \\ t.p.hagen@medisin.uio.no \\ Tor Iversen \\ Tron Anders Moger \\ Avdeling for helseledelse og helseøkonomi \\ Institutt for helse og samfunn \\ Universitetet i Oslo

\begin{abstract}
e-tab 2, e-tab 3, e-tab 4, e-tab 5, e-tab 6, e-tab 7 og e-tab 8 finnes i Tidsskriftets elektroniske utgaver
\end{abstract}

Engelsk oversettelse på www.tidsskriftet.no

HOVEDBUDSKAP

30-dagersoverlevelse etter sykehusinnleggelse for hjerteinfarkt er ett kriterium i kvalitetsbasert finansiering

Bruk av kvalitetsmål i finansieringen forutsetter at variasjoner ikke skyldes bakenforliggende variabler

Dødeligheten varierer med risikojusteringsmetodene

Det trengs godt dokumenterte modeller for risikojustering av kvalitetsmål 
Tabell 1 Beskrivelse av pasientpopulasjonen utskrevet med diagnosen hjerteinfarkt ved norske sykehus i 2009 etter helseforetakenes opptaksområder

\begin{tabular}{|c|c|c|c|c|c|c|}
\hline Helseforetak & $\begin{array}{l}\text { Antall syke- } \\
\text { husepisoder }\end{array}$ & $\begin{array}{l}\text { Insidens } \\
\text { per } \\
10000 \\
\text { inn- } \\
\text { byggere }\end{array}$ & $\begin{array}{c}\text { Andel } \\
\text { døde, } \\
30 \text { dager } \\
(\%)\end{array}$ & $\begin{array}{c}\text { Antall } \\
\text { komor- } \\
\text { biditeter } \\
\text { (gjennom- } \\
\text { snitt) }\end{array}$ & $\begin{array}{c}\text { Andel } \\
\text { menn } \\
(\%)\end{array}$ & $\begin{array}{c}\text { Alder (år) } \\
\text { (gjennom- } \\
\text { snitt) }\end{array}$ \\
\hline $\begin{array}{l}\text { Akershus } \\
\text { universitetssykehus }\end{array}$ & 600 & 33,5 & 9,0 & 1,6 & 61,5 & 69,7 \\
\hline Asker og Bærum & 210 & 16,9 & 5,2 & 1,5 & 56,7 & 75,3 \\
\hline Bergen & 864 & 27,6 & 9,3 & 1,5 & 64,7 & 71,2 \\
\hline Buskerud & 616 & 30,8 & 8,6 & 1,5 & 65,7 & 70,2 \\
\hline Finnmark & 222 & 39,8 & 8,1 & 1,4 & 66,7 & 69,7 \\
\hline Fonna & 474 & 36,9 & 6,9 & 1,5 & 61,6 & 72,0 \\
\hline Førde & 254 & 31,2 & 12,6 & 1,6 & 60,6 & 75,4 \\
\hline Helgeland & 175 & 29,3 & 9,1 & 1,4 & 59,4 & 72,6 \\
\hline Innlandet & 1034 & 33,2 & 9,2 & 1,6 & 62,9 & 72,3 \\
\hline Nord-Trøndelag & 330 & 32,3 & 7,9 & 1,4 & 66,1 & 71,4 \\
\hline Nordland & 346 & 33,6 & 8,1 & 1,6 & 58,4 & 73,4 \\
\hline $\begin{array}{l}\text { Nordmøre } \\
\text { og Romsdal }\end{array}$ & 290 & 32,2 & 7,6 & 1,4 & 55,9 & 74,0 \\
\hline Oslo & 1149 & 20,7 & 8,1 & 1,7 & 56,9 & 73,6 \\
\hline Stavanger & 552 & 22,7 & 8,5 & 1,3 & 65,4 & 69,3 \\
\hline Sunnmøre & 339 & 33,3 & 8,3 & 1,7 & 61,1 & 74,7 \\
\hline Sør-Trøndelag & 631 & 28,0 & 8,6 & 1,5 & 60,4 & 71,6 \\
\hline Sørlandet & 429 & 20,2 & 9,3 & 1,4 & 62,0 & 70,5 \\
\hline $\begin{array}{l}\text { Universitetssyke- } \\
\text { huset Nord-Norge }\end{array}$ & 466 & 33,0 & 8,6 & 1,4 & 66,5 & 70,7 \\
\hline Vestfold og Telemark & 999 & 32,1 & 8,5 & 1,5 & 61,2 & 71,1 \\
\hline Østfold & 737 & 35,0 & 9,1 & 1,7 & 61,2 & 71,0 \\
\hline Hele landet & 10717 & 28,6 & 8,6 & 1,5 & 61,8 & 71,8 \\
\hline
\end{tabular}

populasjon mellom sykehusene ekskluderte vi pasienter som hadde vært innlagt i sykehus for akutt hjerteinfarkt de siste 365 dagene før indeksdagen. Deretter ble data som beskrev pasientens risikoprofil koblet på individnivå. I tillegg til kjønn og alder inngikk følgende variabler i risikojusteringen: komorbiditet, sosioøkonomisk status, prosedyrer, reisetid til nærmeste PCI-senter og type hjerteinfarkt.

Data om sykehusinnleggelser samt datoer for innleggelser og utskrivninger, hoved- og bidiagnoser, komorbiditet og prosedyrer ble hentet fra Norsk pasientregister. Data om dødelighet ble etablert på bakgrunn av informasjon fra Dødsårsaksregisteret. Opplysninger om medikamentbruk ble hentet fra Reseptregisteret. FD-trygd (Statistisk sentralbyrås «Forløpsdatabasen trygd») ga oss tilgang til data om inntekt, formue, utdanning og uførestønad. Data om folketall er fra 31.12. 2009 .

EuroHOPE-prosjektet er godkjent av regional komité for medisinsk og helsefaglig forskningsetikk Sør-Øst. Siden man i prosjektet anvender data fra Reseptregisteret, er det også søkt om og innvilget konsesjon fra Datatilsynet.

\section{Variabler}

Vi etablerte variabler som beskrev komorbiditet på bakgrunn av sykehusdata om innleggelser fra de siste 365 dagene før indeksdagen og data om medikamentbruk fra Reseptregisteret i tilsvarende periode (8). For eksempel ble pasienter med hypertensjon som registrert hoved- eller bidiagnose og pasienter som hadde fått forskrevet legemidler mot hypertensjon registrert med komorbiditeten hypertensjon.

Ved å ta med informasjonen om medikamentbruk i tillegg til registrerte hoved- og bidiagnoser steg andelen pasienter med komorbiditeten hypertensjon i materialet med $50 \%$. Andelen pasienter med diabetes, astma og depresjon steg med om lag $10 \%$. For de resterende komorbiditetene medførte inklusjon av data fra Reseptregisteret bare små endringer.

Sosioøkonomiske forhold ble beskrevet ved variabler som har vist seg å korrelere med hjerteinfarktdødelighet $(10,12,13)$ : inntekt, formue, mottatt uførestønad og utdanning. Inntekt ble definert som gjennomsnittlig samlet personlig bruttoinntekt i perioden 2000-08 og formue som gjennomsnittlig personlig bruttoformue for de samme årene. Det ble registrert om pasienten hadde mottatt uføretrygd i 2008 eller tidligere. Utdanning ble kategorisert i grunnskole, videregående skole og høyskole/universitet.

Hjerteinfarktpasienter får primært trombolytisk behandling eller perkutan koronar intervensjon, et mindre antall åpen hjerteoperasjon (coronary artery bypass surgery, CABG). Pasientene ble klassifisert etter om de fikk trombolytisk eller annen medikamentell behandling eller perkutan koronar intervensjon eller åpen hjertekirurgi. Reisetid i minutter med bil fra kommunesenteret i pasientens hjemkommune til nærmeste PCIsenter ble estimert med utgangspunkt i data fra Google Maps (14). Vi antok ikke-linearitet som følge av at bil- og båtambulanser blir erstattet med helikopter når reisetiden blir lang, anslagsvis over én time (15).

For å bedre sammenliknbarheten i pasientpopulasjonen sykehusene imellom ble type hjerteinfarkt registrert. Sykehusenes klassifisering av pasienter i undergruppene av ICD-systemet er basert på skjønn. Vi estimerte derfor modellene med og uten variablene som beskrev type hjerteinfarkt.

\section{Statistiske analyser}

Deskriptiv statistikk er vist etter helseforetak som gjennomsnitt for kontinuerlige variabler og som andeler for kategoriske variabler. Av plasshensyn viser vi kun gjennomsnittlig antall komorbiditeter per pasient (tab 1). Informasjon om enkeltkomorbiditeter slik de ble brukt i regresjonsmodellene og gruppert etter helseforetak fremgår av e-tabell 2.

$\mathrm{Vi}$ benyttet logistisk regresjonsanalyse med 30-dagersdødelighet som utfallsmål. For å unngå ikke-lineære effekter på logskala ble alle kontinuerlige kovariater kategorisert. Kategoriene for alder var 18-49 år, deretter er det femårige kategorier opp til 89 år og en kategori som omfatter personer $\geq 90$ år. Inntekt og formue ble delt inn i kategoriene kr 0-150 000, kr 150 000-300 000, 
kr 300 000-500 000 og > kr 500 000. Reisetid ble delt inn i kategoriene $0-60 \mathrm{~min}$, 60-120 min, 120-180 min og > 180 min.

Tre modeller for risikojustering ble benyttet $(9,10)$ :

- Modell 1: justering for alder og kjønn

- Modell 2: justering for alder, kjønn, komorbiditeter, sosioøkonomiske variabler, reisetid og type hjerteinfarkt

- Modell 3: alle variablene i modell 2 samt justering for om perkutan koronar intervensjon ble utført i løpet av 14 dager etter innleggelse eller ikke

Variablene ble brukt til å estimere risikojusterte andeler døde med $95 \%$ konfidensintervall $(95 \% \mathrm{KI})$ for hvert helseforetak. For å gi et bilde av hvor godt modellene kunne klassifisere pasienter i datamaterialet riktig, det vil si de døde pasientene som døde og de levende som levende, oppgir vi noen AUC-verdier (area under the curve). En AUC-verdi på 0,5 betyr at modellen ikke klassifiserer bedre enn myntkast.

Data ble tilrettelagt ved hjelp av SAS versjon 9.2 (16) og videre analysert i Stata versjon $12.1(17)$

\section{Andre metodiske forhold}

Analysene er gjort på helseforetaksnivå med utgangspunkt $\mathrm{i}$ helseforetaksstrukturen slik den var første halvår 2009. Pasientene er gruppert etter helseforetak basert på foretakenes opptaksområder. Det innebærer at en pasient med bostedsadresse i en kommune som hørte til et helseforetaks opptaksområde ble klassifisert til dette helseforetaket, uavhengig av hvor pasienten faktisk ble behandlet.

\section{Resultater}

Beskrivelse av pasientpopulasjonen

Etter eksklusjon av pasienter som ble behandlet for akutt hjerteinfarkt i løpet av de siste 365 dagene før indeksdatoen $(n=1718)$, omfattet datamaterialet 10717 pasienter. Tabell 1 viser data for disse pasientene. Utfyllende informasjon om komorbiditeter og sosiodemografiske faktorer finnes i e-tabell 2 og e-tabell 3

Insidensen av hjerteinfarkt (antall tilfeller per 10000 innbyggere) var 28,6 for landet totalt og varierte fra 16,9 i helseforetaket Asker og Bærums opptaksområde til 39,8 i Helse Finnmarks opptaksområde. Landsgjennomsnittet for ujustert 30-dagersdødelighet var 8,6\% - høyest i Helse Førde $(12,6 \%)$ og lavest i Asker og Bærum $(5,2 \%)$. Forekomsten av enkeltkomorbiditeter varierte betydelig mellom helseforetakene (e-tab 2).

\section{Logistiske regresjonsanalyser}

Figur 1 viser ujusterte andeler døde etter 30 dager samt tilsvarende justerte andeler

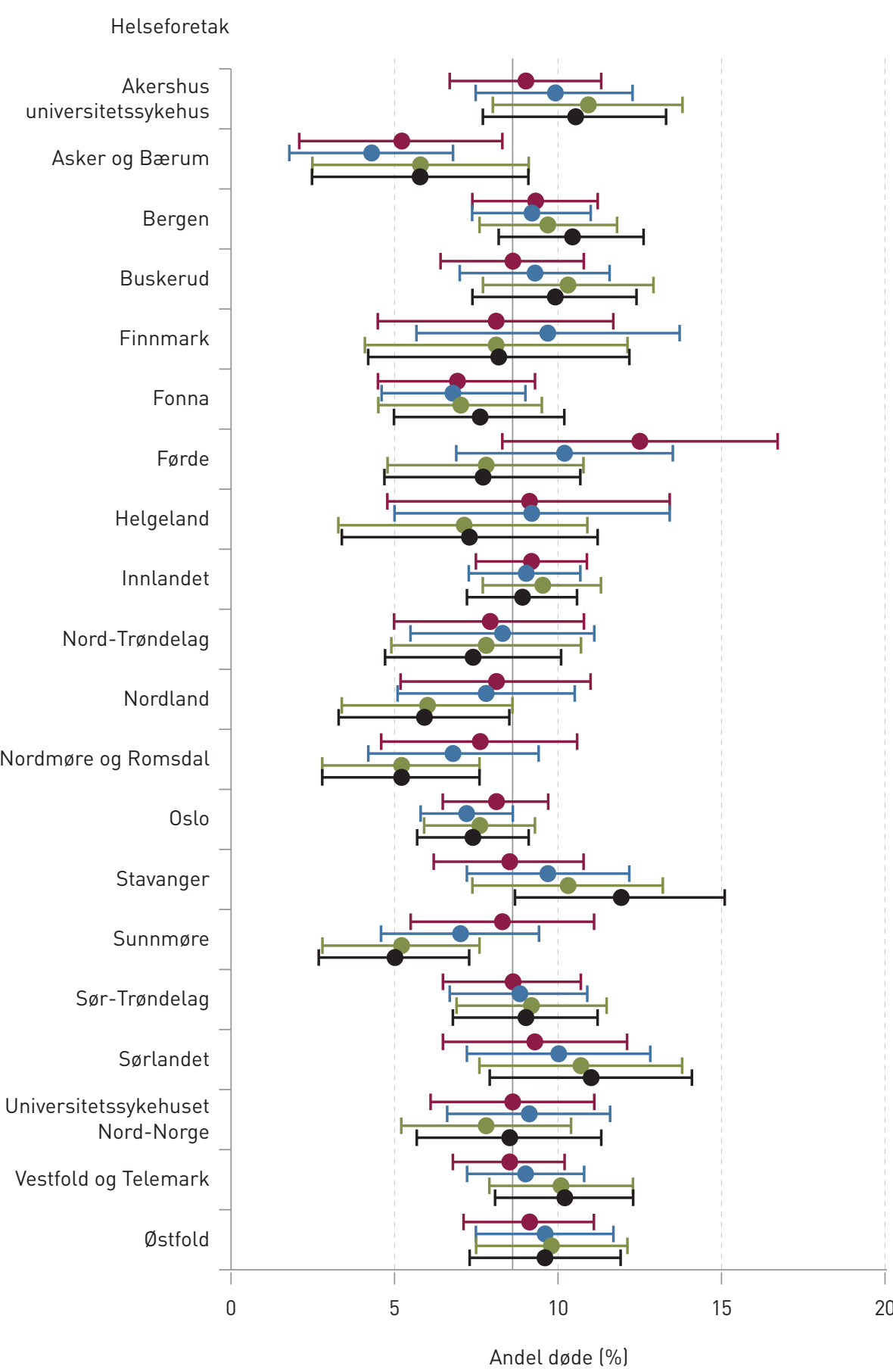

Ujusterte tall

Justert for alder og kjønn

Justert for alder, kjønn, type hjerteinfarkt, komorbiditet, reiseavstand og sosioøkonomiske faktorer

Justert for alle foregående variabler samt perkutan koronar intervensjon etter 14 dager

Figur 1 Andel døde etter 30 dager per helseforetak med $95 \%$ konfidensintervall hos pasienter utskrevet med diagnosen hjerteinfarkt ved norske sykehus i 2009. Vertikal linje angir landsgjennomsnittet. Røde og blå linjer: $N=10$ 717. Grønne og svarte linjer: $N=10379$ 
for de tre ulike tilnærmingene for risikojustering. Nøyaktige tall og utfyllende informasjon om regresjonskoeffisientene finnes $i$ e-tabell 4-7. Gjennomgående var det få konfidensintervaller for enkelthelseforetakene som ikke dekket landsgjennomsnittet på $8,6 \%$ for 30 -dagersdødelighet. Unntakene var pasientene i opptaksområdet til Helse Asker og Bærum i den ujusterte analysen og $\mathrm{i}$ analysen der det er justert for kjønn og alder samt pasientene i opptaksområdene til Helse Nordmøre og Romsdal og Helse Sunnmøre. De to siste gruppene hadde en dødelighet på 5,2\% etter risikojustering for alle kovariater.

Forekomsten av perkutan koronar intervensjon og/eller åpen hjerteoperasjon etter to og 14 dager fordelt på aldersgruppe og helseforetak viste at førstnevnte behandling gjennomgående var vanligere $\mathrm{i}$ helseforetakene som har eget PCI-senter enn i de andre foretakene (e-tab 8).

Den ujusterte modellen hadde en AUCverdi på 0,53 , det vil si på nivå med myntkast. Da vi la til alder og kjønn, steg verdien til 0,76 . Den steg videre til 0,80 da vi inkluderte type hjerteinfarkt, komorbiditeter, sosioøkonomiske variabler og reiseavstand, og til 0,81 da vi også inkluderte perkutan koronar intervensjon etter 14 dager.

\section{Diskusjon}

Bruk av kvalitetsbasert finansiering, der data om overlevelse inngår i kvalitetsindikatorene, kan føre til at sykehusene oppmuntres til å behandle pasienter der det er grunn til å forvente gode resultater. Dersom det ikke blir kontrollert for bakgrunnsvariabler, vil dette kunne føre til feilallokering av ressurser. Manglende risikojustering kan derfor være til ulempe både for pasienter med alvorlig sykdom som er vanskelig å behandle og for sykehusene som behandler disse pasientene. For eksempel er det vist at introduksjon av kvalitetsindikatorer for hjertekirurgi i New York og Pennsylvania førte til seleksjon av pasienter blant sykehusene (18).

I modellen som er benyttet til kvalitetsbasert finansiering i Norge, er det ikke klargjort hvordan risikojusteringen er foretatt (3). Målet med denne studien var derfor å undersøke hvordan ulike former for risikojustering påvirket predikert dødelighet - med pasienter utskrevet med diagnosen akutt hjerteinfarkt som eksempel.

Hovedkonklusjonene fra analysen er at kjønn, alder, komorbiditet, uførhet og reisetid er kandidater til variabler det bør justeres for. Andre variabler som vi ikke har hatt tilgang til, for eksempel informasjon om genetiske forhold (19), kan i tillegg være relevante. De sosioøkonomiske variablene ga mindre bidrag til risikojusteringen etter at de førstnevnte variablene var inkludert.
Selv om denne analysen har begrenset statistisk styrke og det var få konfidensintervaller for enkelthelseforetak som ikke dekket landsgjennomsnittet for 30-dagersdødelighet, så er endringene som følge av risikojusteringene viktige for hvordan ressurser gjennom kvalitetsbasert finansiering allokeres. Den estimerte dødeligheten ble betydelig endret for pasienter i opptaksområdene til helseforetakene Asker og Bærum, Stavanger, Sunnmøre, Nordmøre og Romsdal og også Førde når flere variabler ble inkludert. Analysens hovedkonklusjon er derfor at man bør kontrollere for et bredt spekter av bakenforliggende variabler både når kvalitetsinformasjon offentliggjøres og når kvalitetsindikatorer skal benyttes som grunnlag for finansieringssystemet.

I den normative debatten om hvordan kvalitetsbaserte finansieringssystemer skal utformes, stilles det blant annet spørsmål ved om prosedyrebruk skal inngå som kvalitetsindikator (20). Den eneste variabelen vi hadde med $\mathrm{i}$ analysen som kan knyttes til behandlingen ved helseforetaket, var perkutan koronar intervensjon.

To forhold gjør at det ikke er åpenbart at belønning for denne type behandling er en god løsning: Det kan lede til overbehandling og det vil gi geografisk skjevfordeling av ressurser som følge av dagens PCI-senterstruktur, da metoden er vanligere i helseforetak som har PCI-senter enn i helseforetak som ikke har noe slikt senter. Dette gjelder også for perkutan koronar intervensjon etter 14 dager og reflekterer både mulighetene for akuttbehandling med metoden og den forventede effektiviteten av slik behandling etter akuttfasen. Listen over prosedyrer som kan tas med i analysen kan imidlertid utvides. For hjerteinfarktpasienter kan rehabilitering, kontroller og medikamentbruk være relevante prosedyrevariabler.

Mens beslutningen om perkutan koronar intervensjon tas på klinisk nivå i sykehuset, vil flere andre variabler kunne påvirkes på lokalt eller regionalt nivå $\mathrm{i}$ helseforetakssystemet. Ett eksempel er reisetid til PCIsenteret. Dersom lange avstander leder til høyere dødelighet og man velger å justere for avstander $\mathrm{i}$ en fordelingsmodell, kan dette isolert sett lede til at man premierer sentralisering av aktivitetene. Størrelsen på helseforetakene er et annet eksempel på forhold som kan påvirkes og som vil kunne innvirke på resultatene av den type analyser vi har gjort. Dersom analysene gjøres med utgangspunkt i helseforetakenes opptaksområder, vil store helseforetak isolert sett lede til mindre variasjon mellom foretakene enn flere små helseforetak.

Vår analyse representerer et eksempel på hvordan risikojustering kan gjennomføres for å gi grunnlag for kvalitetsbasert finansiering.
Analysen har begrensninger. Ideelt sett burde vi brukt data fra flere år for å øke styrken. Resultatene viser likevel konfidensintervaller for enkelte helseforetak som ikke dekker landsgjennomsnittet hvis de har en dødelighet som ligger 3-4\% over eller under dette. Et viktig spørsmål som ikke er avklart, er hvor mye dødeligheten for det enkelte helseforetak skal avvike fra landsgjennomsnittet før det får effekt på budsjettildelingen til de regionale helseforetakene.

Data må også være så aktuelle som mulig, slik at de ansatte ved sykehusene kan se finansielle effekter av kvalitetsendringer i løpet av ett år eller to. Av praktiske årsaker, særlig den tiden det tar å få behandlet konsesjoner om datatilgang og å hente ut data, har vi her benyttet data fra 2009. Det har skjedd forbedringer $\mathrm{i}$ akuttberedskapen de siste årene. Resultatene av analysen kunne derfor ha blitt noe annerledes i dag. Reisetidsvariabelen vi har benyttet, kan også forbedres ved å inkludere data på pasientnivå fra databasen som registrerer informasjon om ambulanseturer (Akuttmedisinsk informasjonssystem, AMIS).

I denne studien har vi tatt utgangspunkt $\mathrm{i}$ helseforetakenes sørge-for-ansvar. Det innebærer at pasientens bostedsadresse avgjør hvilket helseforetak en pasient tilhører. Nasjonalt kunnskapssenter for helsetjenesten tar utgangspunkt i behandlingssted, vektet etter liggetid hvis det er flere behandlingssteder, i sine analyser av overlevelse og reinnleggelser ved norske sykehus.

Disse to ulike innfallsvinklene får konsekvenser for hvem som holdes ansvarlig for behandlingsutfallet for pasienten. Mens vi gir ansvaret til det helseforetak som i praksis har sørge-for-ansvaret for pasienten, gir Kunnskapssenteret ansvaret til det behandlingssted eller det helseforetak som faktisk utfører behandlingen. I kvalitetsbasert finansiering er det viktig å ha en gjennomtenkt oppfatning av om man vil velge den ene eller den andre innfallsvinkelen. $\mathrm{Vi}$ ser ingen grunn til at finansieringen på dette punkt skal avvike fra prinsippene som er valgt for finansiering av helseforetakene generelt.

Vi takker våre kliniske eksperter Morten Grundtvig, Asmund Reikvam og Cecilie Risøe for diskusjon av operasjonaliseringer og pasientforløp for hjerteinfarktpasienter. Alle vurderinger står for forfatternes regning.

Analysen er finansiert av NFR-prosjekt 191390 More for less og EUs 7. rammeprogram, prosjekt 241721 EuroHOPE. 


\section{Terje P. Hagen (f. 1957)}

er cand.polit. og dr.polit. i statsvitenskap og professor. Han har bidratt med idé, utforming/ design, datainnsamling, fortolkning av data, litteratursøk, utarbeiding/revisjon av manuskriptet og har godkjent innsendte manusversjon.

Forfatter har fylt ut ICMJE-skjemaet og oppgir ingen interessekonflikter.

\section{Tor Iversen (f. 1952)}

er cand.oecon. og dr.polit. i samfunnsøkonomi og professor. Han har bidratt med design, datainnsamling, fortolkning av data, litteratursøk, utarbeiding/revisjon av selve manuskriptet og har godkjent innsendte manusversjon. Forfatter har fylt ut ICMJE-skjemaet og oppgir ingen interessekonflikter.

\section{Tron Anders Moger (f. 1975)}

er m.sc. og ph.d. i statistikk og førsteamanuensis. Han har bidratt med analyse av data, fortolkning av data, utarbeiding/revisjon av selve manuskriptet og har godkjent innsendte manusversjon.

Forfatter har fylt ut ICMJE-skjemaet og oppgir ingen interessekonflikter.

\section{Litteratur}

1. Meld. St. 10 (2012-2013). God kvalitet - trygge tjenester - Kvalitet og pasientsikkerhet i helseog omsorgstjenesten. www.regjeringen.no/no/ dokumenter/meld-st-10-20122013/id709025/ (23.1.2016)

2. Prop. 1 S (2013-2014). Gul bok. For budsjettåret 2014. www.regjeringen.no/no/dokumenter/ prop-1-s-20132014--2/id739677/ (23.1.2016).

3. Kiviluouta L, Arneberg F. Kvalitetsbasert finansiering 2014. Oslo: Helsedirektoratet, 2013.

4. Mason A, Street A. Publishing outcome data: is it an effective approach? J Eval Clin Pract 2006; 12: $37-48$

5. Smith PC, Street AD. On the uses of routine patientreported health outcome data. Health Econ 2013; 22: $119-31$

6. Häkkinen U. The PERFECT project: measuring performance of health care episodes. Ann Med 2011; 43 (suppl 1): S1-3.

7. Häkkinen U, Hartikainen J Juntunen $M$ et al. Analysing current trends in care of acute myocardial infarction using PERFECT data. Ann Med 2011; 43 (suppl 1): S14-21.

8. Häkkinen U, Iversen T, Peltola M et al. Health care performance comparison using a disease-based approach: the EuroHOPE project. Health Policy 2013; 112: 100-9

9. Hagen TP, Häkkinen U, Belicza E et al. Acute myocardial infarction, use of percutaneous coronary intervention and mortality: A comparative effectiveness analysis covering seven European countries. Health Econ 2015; 24 (suppl 2): 88-101.

10. Hagen TP, Häkkinen U, Iversen T et al. Socioeconomic inequality in the use of procedures and mortality among AMI-patients: Quantifying the effects along different paths. Health Econ 2015; 24 (suppl 2): 102-15

11. Peltola M, Juntunen $M$, Häkkinen $U$ et al. A metho- dological approach for register-based evaluation of cost and outcomes in health care. Ann Med 2011; 43 (suppl 1): S4-13

12. Alter DA, Franklin B, Ko DT et al. Socioeconomic status, functional recovery, and long-term mortality among patients surviving acute myocardial infarction. PLoS ONE 2014; 8: e65130.

13. Bernheim SM, Spertus JA, Reid KJ et al. Socioeconomic disparities in outcomes after acute myocardial infarction. Am Heart J 2007; 153: 313-9.

14. Ozimek A, Miles D. Stata utilities for geocoding and generating travel time and travel distance information. Stata J 2011; 11: 106-19.

15. Strømsøe V. Do place and socio economic status matter? Analysis of inequalities in the probability of PCI for AMI in Norway 1999-2007 with respect to geographical location, socio economic status and demography. Oslo: Avdeling for helseledelse og helseøkonomi, Institutt for helse og samfunn, Universitetet i Oslo.

16. SAS (R) 9.2 Language Reference. 4. utg. Cary, NC: SAS Institute, 2011

17. StataCorp. Stata Statistical Software: Release 12 College Station, TX: StataCorp, 2011.

18. Dranove D, Kessler D, McClellan M et al. Is more information better? The effects of «Report cards» on health care providers. J Polit Econ 2003; 111: 555-88.

19. Ranthe MF, Petersen JA, Bundgaard $\mathrm{H}$ et al. A detailed family history of myocardial infarction and risk of myocardial infarction - a nationwide cohort study. PLoS ONE 2015; 10: e0125896.

20. Maynard A. The powers and pitfalls of payment for performance. Health Econ 2012: 21:3-12.

Mottatt 6.10. 2013, første revisjon innsendt 19.6 2014, godkjent 23.1. 2016. Redaktør: Lars Frich. 